Wilfrid Laurier University

Scholars Commons @ Laurier

Kinesiology and Physical Education Faculty

Publications

Kinesiology and Physical Education

$6-2000$

\title{
Examining the Relationships Among Concepts of Control and Exercise Attendance
}

Kimberley A. Dawson

Wilfrid Laurier University, kdawson@wlu.ca

Lawrence R. Brawley

University of Waterloo

James E. Maddux

George Mason University

Follow this and additional works at: https://scholars.wlu.ca/kppe_faculty

\section{Recommended Citation}

Dawson, Kimberley A.; Brawley, Lawrence R.; and Maddux, James E., "Examining the Relationships Among Concepts of Control and Exercise Attendance" (2000). Kinesiology and Physical Education Faculty Publications. 2.

https://scholars.wlu.ca/kppe_faculty/2

This Article is brought to you for free and open access by the Kinesiology and Physical Education at Scholars Commons@ @aurier. It has been accepted for inclusion in Kinesiology and Physical Education Faculty Publications by an authorized administrator of Scholars Commons @ Laurier. For more information, please contact scholarscommons@wlu.ca. 


\title{
Examining the Relationships Among Concepts of Control and Exercise Attendance
}

\author{
Kimberley A. Dawson \\ Wilfrid Laurier University
}

\author{
Lawrence R. Brawley \\ University of Waterloo
}

\section{James E. Maddux \\ George Mason University}

\begin{abstract}
Many researchers in psychology and physical activity have discussed the overlap among control constructs in various theories. Skinner (1996) proposed an integrative control framework based on an agent-means-ends distinction that offered comparisons among and more explicit measurement of 3 control constructs-control, capacity, and strategy beliefs. No study in the exercise domain has yet empirically examined these advantages. This study evaluated Skinner's framework relative to their contribution to predicting exercise attendance. A prospective design was used to consider the potential change in the nature of the relationships. High correlations (range $r=.52-.88$ ) at 2 time points in the exercise program suggested overlap among control constructs when using Skinner's measurement procedures. Only capacity beliefs and behavioral intention were significantly related to exercise attendance (model $R_{\text {adjusted }}^{2}=.11$ and $.16, p=.03$ and .01 , respectively, at onset and midprogram). The findings do not support Skinner's contentions but are similar to previous findings in the exercise literature.
\end{abstract}

Key words: control constructs, exercise, behavioral intention

The construct of personal control has intrigued psychologists for years because of its assumed role in influencing motivated human behavior. Whether the field of research concerns everyday behavior, high-performance sport, health, or exercise-related behavior, control is often examined with respect to its motivational influence. Skinner (1996), however, has clearly illustrated that a burgeoning psychological literature of more than 100 control constructs is one cause of conceptual confusion in the study of personal control. As a result of this confusion, there might often be instances in which highly similar constructs with different names are found in the same research literature.

K.A. Dawson is with the Department of Kinesiology and Physical Education at Wilfrid Laurier University, Waterloo, Ontario, Canada N2L 3C5. L.R. Brawley is with the Department of Kinesiology at the University of Waterloo, Waterloo, Ontario, Canada N2L 3G1. J.E. Maddux is with the Department of Psychology at George Mason University, Fairfax, VA 22030. 
Numerous researchers in psychology (cf. Bandura, 1997; Barone, Maddux, \& Snyder, 1997; Skinner, 1996) and in the areas of health, exercise, and sport (Biddle, 1999; Dawson, Gyurcsik, Culos-Reed, \& Brawley, in press; Maddux, Brawley, \& Boykin, 1995) have advanced comparative discussions of the similarities and overlaps of control constructs in various theories and studies. To illustrate the scope of the literature, consider the following brief example of a commonly recognized model with multiple control-related concepts. Bandura $(1986,1997)$ proposed a social-cognitive theory of reciprocal causation. Three concepts that relate to control are central to this theory. One such concept is self efficacy-beliefs about capabilities to exercise control over events, behavior, and actions. A second concept is goal cognitions, which, through standards and forethought, motivate and guide action. A third concept is outcome expectations, which represent an individual's vision of what he or she will attain as a function of motivated actions. These three concepts about control are used within a single model.

Another example of the scope of control constructs is their prevalence in the numerous models used to study exercise and health psychology. Regardless of the theory chosen as the basis for any given study of physical activity, behavioral control is prominently featured (e.g., health belief model: Rosenstock, 1974; Strecher, Champion, \& Rosenstock, 1997; protection motivation theory: Rogers, 1975; Rogers \& Prentice-Dunn, 1997; theory of planned behavior: Ajzen, 1988; self-efficacy theory: Bandura, 1997). A comparison of control concepts in these models has been discussed extensively elsewhere (e.g., Biddle, 1999; Dawson et al., in press; Maddux, 1993; Maddux et al., 1995), but it is clear that the prevalence of similar concepts has motivated these comparative discussions of overlap and similarity.

Skinner (1996) suggested an across-theory integrative framework in which she offered a solution to conceptual prevalence and confusion in the literature. A central objective of Skinner's proposal was to offer the field of social psychology some order in categorizing and clarifying the more than 100 terms and concepts used to describe control. Skinner suggested that the potential outcomes of her integrative framework are (a) to allow comparisons among control constructs and (b) to allow for more explicit measurement of such constructs. These outcomes are highly desirable in research and, in particular, for remedying the problem in linking concepts to operational definitions-one of the most common research maladies in behavioral science (Brawley, 1993). The specific issue we attempt to empirically address is whether the conceptual distinction outlined by Skinner (1996) actually offers more explicit measurement and, thus, better prediction of behaviorrelated dependent measures.

\section{Conceptual Clarity or Further Confusion?}

In order to appreciate Skinner's (1996) ideas, a brief explanation of some of the types of control beliefs she describes in her guide is instructive. The framework proposed by Skinner (1996) outlines similarities and distinctions among concepts of control based on agent-means-ends relationships. The beliefs that reflect these various relationships she proposes are conceptually distinct from one another.

First, control beliefs concern the agent-ends relationships. They are appraisals or expectancies about the extent to which an individual can achieve desired 
outcomes. Operationally, these beliefs make no explicit reference to the behavior used to achieve the outcome. They are based on evaluations of the probability of reaching targeted outcomes. A measurement example of a statement reflecting a control belief would be "I am confident that I can lose weight."

The second type of belief proposed by Skinner (1996) is a capacity belief. Capacity beliefs concern the agent-means relationship in the integrative framework. They are defined as an individual's expectancies about the extent to which he or she possesses or can call into action specific behaviors (means). A measurement example of an item reflecting an exercise-related capacity belief is "I am confident that I can exercise regularly over the next 3 weeks." Note that no reference is made to an outcome as in the other two types of belief. Conceptually and operationally, capacity beliefs are similar to self-efficacy beliefs.

The third type of belief outlined by Skinner (1996) is a strategy belief. Strategy beliefs concern the means-ends relationship in Skinner's framework. They are defined as an individual's expectations about the extent to which certain behaviors (means) are effective in producing desired outcomes. Both control and strategy beliefs involve outcomes or endpoints. However, the conceptual and operational difference between control and strategy beliefs is that there is no reference to the behavior necessary to obtain outcomes in the control belief. By contrast, strategy beliefs involve consideration of the means necessary to obtain the outcome. A measurement example of an item that exemplifies the operational definition of a strategy belief is "I am confident that if I exercise regularly for the next 3 weeks, I will lose weight." Strategy beliefs are similar to outcome expectations as outlined by Bandura $(1986,1997)$.

By focusing researchers on explicit measurement of the concepts, Skinner's proposals provide the opportunity to empirically consider the beliefs she proposes. This is part of the overall objective of the present study.

\section{Empirical Examination of Exercise Control Beliefs}

Although Skinner argues for three distinct kinds of beliefs (i.e., control, strategy, and capacity), it is not clear whether individuals cognitively separate these beliefs. Biddle (1999) has noted that the measurement of control beliefs is not as common in the exercise literature as that of either capacity or strategy belief (i.e., recall capacity beliefs are like self-efficacy beliefs, whereas strategy beliefs are like outcome expectations). Indeed, it can be argued that individuals make the link between outcomes and actions to achieve outcomes even when outcomes alone are examined (cf. Bandura, 1997). The purpose of the present study, therefore, was to examine whether the control belief distinctions that Skinner proposes offer the exercise literature explicit measurement advantages and whether these measures appear to be an advantage for the prediction of exercise-related dependent measures.

It is argued that Skinner's control beliefs do not offer explicit measurement advantages that make these three types of beliefs distinct. Thus, we hypothesized that there would be a strong correlation between the various measures of Skinner's beliefs. Furthermore, of the three beliefs of perceived control, we hypothesized that capacity beliefs would most likely predict exercise-related dependent measures. If capacity beliefs are similar to self-efficacy beliefs (at least by virtue of their operational definition), they should empirically function in a manner like that 
of efficacy beliefs. Consistent with observations found in the efficacy literature, they should predict behavior.

The comparative analyses of theories that were mentioned earlier (e.g., Bandura, 1997; Biddle, 1999; Maddux et al., 1995), however, also refer to the inclusion of another social cognition that can add to the prediction of behavior, that is, the concept of behavioral intention. Bandura (1997) argues that behavioral intention is a proximal goal that makes an independent contribution to the motivation of actions and performance. This relationship has been empirically demonstrated in physical activity research (e.g., DuCharme \& Brawley, 1995; Poag-DuCharme \& Brawley, 1993). Therefore, if Skinner's control concepts are to receive a fair empirical examination, and this examination is consistent with the relation of control constructs to behavior in the existing literature, it would be prudent to include intention when predicting exercise behavior.

Recall that the purpose of Skinner's (1996) framework is to both clarify and provide more explicit measurement, thus leading to clearer distinctions about the relationships of measures of control variables with measures of other constructs. If this is true, the relationship of the specific control measures to behavior could be (a) independent or (b) joint with behavioral intention. If only the independent prediction of the control beliefs were demonstrated, it could be claimed that their effects on behavior would vanish with the inclusion of intention. Conversely, if their independent effect were not demonstrated, it could also be argued that a fair examination had not been conducted because the control constructs act jointly with intention to predict behavior (i.e., in a multiple-regression model that examined a control measure plus intention).

Therefore, it was also our hypothesis that capacity beliefs (i.e., the concept and measure most similar to efficacy) would act in an additive fashion with intention to predict attendance behavior (i.e., hierarchically in a multiple-regression model), similar to the efficacy-behavior relationship previously observed in the exercise literature (e.g., DuCharme \& Brawley, 1995). In summary, it was anticipated that no measurement advantage and corresponding opportunity to detect control-behavior relationships as advanced by Skinner (1996) would be observed.

\section{Method}

\section{Participants and Designs}

Participants for this prospective study were 116 healthy adults $(20$ men, 96 women) with a mean age of 27 years ( \pm 4 years) who were registered in eight different intermediate-level fitness classes. These classes were offered two or three times a week for $45 \mathrm{~min}$ in duration at a moderate intensity level. A recent consensus paper and position statement by the American College of Sports Medicine (Pollock et al., 1998) identified this exercise dose as a sufficient stimulus for developing and maintaining fitness in healthy adults. More women than men in the sample represented typical fitness-class demographics. Some participants had taken the classes previously $(n=72)$, and others were first-time participants $(n=44)$.

The study design was prospective-observational. Self-regulatory beliefs are not static (Barone et al., 1997) but are dynamic and capable of changing over time. In order to consider the nature and reliability of the hypothesized relationships, a 
prospective design that included two assessments (at program onset and midprogram) was adopted.

\section{Measures}

The explicit measurement distinction (cf. Skinner, 1996) among the three types of beliefs - control, capacity, and strategy beliefs-was a critical aspect of the study. Therefore, particular attention was given to the wording and ordering of measures. All measures were operationally defined for the participants consistent with the definitions and conceptualizations provided by Skinner, Chapman, and Baltes (1988) and Skinner (1996). The measurement differentiation between control beliefs and strategy beliefs is that strategy beliefs specifically link action to specific outcomes, whereas control beliefs are assessed as generalized goals without the action-to-outcome link.

Control Beliefs. The first control measure was designed to assess expectations about the extent to which the agent (e.g., the self) can obtain desired endpoints (cf. Skinner, 1996). The participants were given a list of 10 general exercise-related endpoints developed through pilot testing with similar participants. These endpoints have also been found to be reliable and valid for use with exerciseclass participants in previously published studies (e.g., Dawson \& Brawley, 2000; Poag-DuCharme \& Brawley, 1994). Example endpoints were to get fit, lose or maintain weight, and decrease stress. These endpoints were described to the participants as goals that might or might not be achieved by participating in a semester of intermediate-level fitness classes. Thus, as described by Skinner (1996), these ends are the result of longer term activity involvement and are generalized control beliefs in relation to a period of time (e.g., semester). Participants responded to each item by indicating how confident they were that they could achieve each one of the 10 endpoints on a $100 \%$ confidence scale. A rating of zero indicated very little confidence in their ability, and 100 represented complete confidence (responses were presented in increments of 10). A mean control belief measure was computed based on the responses to the 10 endpoint items (Cronbach's alpha $=.88$ and .90 for Weeks 1 and 6 , respectively). An example of a control belief statement was "How confident are you that you can lose weight in the next 5 weeks?"

Capacity Beliefs. The second control measure was constructed as described by Skinner (1996) and was designed to evaluate expectations about the extent to which agents possess potential means that must be employed toward specific goals. This method is highly similar to the method suggested by Bandura $(1977,1986$, 1997), in which participants rate confidence in performing a specific behavior (i.e., self-efficacy beliefs). Each item reflected the participants' perceived confidence in their ability to complete specific exercise-related behaviors. The participants were provided with a list of behaviors associated with fitness-class participation. The behavior statements were drawn from instruments used in published research studies with similar participants (Dawson \& Brawley, 2000; DuCharme \& Brawley, 1995; Poag-DuCharme \& Brawley, 1993). They were also consistent with recommendations advanced in a recent review by McAuley and Mihalko (1998).

Six statements typified necessary in-class exercise behaviors that characterized the components of the intermediate-level exercise classes (e.g., completing 
the aerobic or strength component of the class). Another six statements represented various planning and scheduling strategies required to attend the fitness class (e.g., getting to class on time and organizing work or school around class). Participants were instructed to consider each specific behavior as it applied to them. Both inclass and scheduling behavior measures were included to adequately represent the range of behaviors reflective of capacity beliefs. Participants used a 100-point confidence scale to respond to all 12 behavior statements, on which a rating of zero indicated low confidence and a rating of 100 indicated high confidence. A mean capacity belief score was computed on the 12 behavior statements (Cronbach's alpha $=.83$ and .80 for Weeks 1 and 6 , respectively). An example capacity belief statement was "How confident are you that you can organize your time/work around each fitness class for the next 5 weeks?"

Strategy Beliefs. The third control measure was designed to evaluate expectations about the extent to which certain specific behaviors produce outcomes or ends. In order to link means and ends, specific actions (i.e., those mentioned previously as in-class and scheduling) are presented as capable of causing certain outcomes (cf. Skinner, 1996).

The same list of 10 endpoints used in the control beliefs measure was presented to the participants in the section immediately after the exercise behaviors, and these outcomes (endpoints) were described to the participants as things that could result from successfully completing the previous exercise behaviors. Participants were asked to consider each endpoint as it would apply to them if they completed the exercise behaviors. Using a $100 \%$ probability scale ranging from zero (not at all likely) to 100 (very likely), the participants indicated the likelihood of each outcome (e.g., lose weight, decrease stress) occurring as a result of engaging in the previous exercise behaviors (e.g., completing the aerobic section of the class, getting to class on time). A mean strategy belief measure was computed on the 10 endpoints (Cronbach's alpha $=.92$ and .85 for Weeks 1 and 6, respectively). An example strategy belief statement was "How likely is it that you will lose weight as a result of completing the previously listed exercise behaviors in the next 5 weeks?"

Behavioral Intention. Recall that an intention is what one plans to do, a proximal goal that makes an independent contribution to the motivation of action (cf. Bandura, 1997; Maddux et al., 1995; Maddux \& DuCharme, 1997). Exercise research based on several studies has shown that intentions are good predictors of exercise behavior both independently and in combination with other social cognitions (cf. DuCharme \& Brawley, 1995; Godin, 1993; Hausenblas \& Carron, 1999; Maddux \& DuCharme, 1997).

Three intention statements were presented to participants. Each concerned an exercise attendance frequency. Frequencies of one, two, or three times per week were presented to the individual. An example intention statement was "I intend to attend one fitness class per week for the next 5 weeks." Participants then indicated the degree of their agreement with each of the intended frequency statements on 1-9 agreement scales. A rating of 1 indicated low agreement, and a rating of 9 indicated high agreement. Participants then circled the statement that best reflected their agreement with the intended frequency. The agreement rating for this statement represented the strength of the intent to complete the self-selected exercise frequency. The circling of the most strongly agreed-on frequency was included to heighten intention saliency and thereby underscore the individual's intention choices. Because not all people intend to partake in all the classes available to 
them, participants considered all three statements before making their responses. This overall measurement procedure was selected to attend to the measurement issues associated with behavioral intention that have been identified by various researchers (Godin, 1993; Courneya \& McAuley, 1993; Maddux \& DuCharme, 1997; Poag-DuCharme, Brawley, Rodgers, \& Robinson, 1992). Intention, as a proximal specific goal, is represented along frequency and strength dimensions and is self-selected from a range of goals. ${ }^{1}$

Exercise Attendance. During each class, participants recorded their attendance on a wall chart, which was monitored daily for accuracy by the class instructor. This observation of actual attendance frequency was chosen to avoid inherent problems of self-report. Because classes were held either two or three times per week, attendance was standardized for statistical analyses by calculating an attendance percentage. For example, a person might have attended two classes for 1 week; if the class was only offered two times per week, this individual would be scored as attending $100 \%$ of the classes offered. However, if the participant was registered in a class that ran three times per week, they would be recorded as attending $66 \%$ of their scheduled fitness classes for the week. Two weekly attendance periods were examined. The mean was calculated separately for the first 5week period (Weeks 1-5) and the second 5-week period (Weeks 6-10).

\section{Procedure}

Participants were enrolled in fitness classes organized by a campus recreation department. They were assessed at program onset and midprogram. On the first exercise meeting, participants agreeing to take part in the study completed the first questionnaire under the supervision of a trained research assistant. At Week 6 , halfway through the program, a second inventory was completed. All control construct questions referred to the attendance period immediately after the assessment. Participants recorded their own attendance daily on a wall chart, with

${ }^{1}$ Intentions best predict behavior when they are measured with a specific action, time, and context. Their conceptualization as proximal goals narrows the range of operational items needed to adequately represent the construct. If a certain frequency of attendance in a specific context within a specific period of time is the proximal goal, the two dimensions needed to adequately represent the attendance intention are frequency and the likelihood or strength of intention associated with that attendance frequency. Thus, only a few items represent the intention construct. If the experienced exerciser is considered as an example, low frequencies of attendance are never in doubt and are not really proximal goals toward which to strive. Higher attendance frequencies are desired goals. Thus higher frequency intent with some possibility of challenge offers more motivational incentive. Participants in the current study had to first consider more than one intention item, then choose a frequency goal that was desired. Thus, participants had the complete range of the frequency and strength dimensions concept represented. The procedure, therefore, (a) represents the construct along two dimensions, (b) provides the participant with the opportunity to best represent his or her desired proximal goal, (c) addresses the issue of correspondence between intention and behavior raised in the literature, and (d) is psychometrically sufficient to represent intention. In contrast, multiple items averaged to represent the construct might bias representation of the participant's actual goal. 
careful monitoring by the class instructors throughout the exercise program. Beliefs and behavioral intention assessed at Week 1 (onset) were used to predict attendance for Weeks 1-5 of the program, and these same variables assessed again at Week 6 (midprogram) were used to predict attendance for Weeks 6-10.

\section{Results}

ANOVA statistical procedures were performed to examine between-class differences. No differences were observed among classes for all primary variables. Therefore, the classes were collapsed for further analyses of the total sample.

\section{Descriptive Statistics}

Table 1 illustrates the various means and standard deviations of the assessed variables. Participants provided responses that were well above the midpoint of the scales for control and strategy beliefs at both onset and midprogram. Similarly, participants were quite efficacious about completing the requisite exercise-related actions (capacity beliefs). The mean adherence rate (i.e., percentage of classes attended) by participants $(N=116)$ was relatively high for the first 5 weeks of the program $(72 \%)$. That rate declined to $41 \%$ (weekly attendance) for program adherers during Weeks 6-10, during the second half of the session. The overall study retention rate was $62 \%$ at the conclusion of the 10 -week program, which parallels other reports in the exercise literature (cf. Dishman, 1988, 1994).

\section{Correlations Among Three Types of Beliefs and Behavioral Intention}

If the three types of beliefs are unique and conceptually distinguishable by participants, as argued by Skinner (1996), then the amount of shared variance among constructs should be minimal. In contrast, support for the hypothesis would indicate potential conceptual overlap, as empirically reflected by high correlations.

Table 1 Means (SDs) of Measures

Measure $\quad$ Program onset Midprogram \% weekly attendance

$\begin{array}{lcc}\text { Control beliefs } & 73.2(11.7) & 74.0(10.1) \\ \text { Strategy beliefs } & 76.6(11.2) & 74.9(8.7) \\ \text { Capacity beliefs } & 83.3(9.6) & 84.7(8.5) \\ \text { Behavioral intention } & 8.5(1.1) & 8.2(1.0) \\ \text { Weeks 1-5 } & & \\ \text { Weeks 6-10 } & & \end{array}$

Note: Program onset time $1 n=116$, and midprogram time $2 n=72$. Weekly attendance rates reflect the participation of exercise adherers. 
Table 2 highlights the correlations among the control beliefs, behavioral intention, and attendance. The results suggest strong conceptual relationships among measures of beliefs in contrast to the explicit measures outlined by Skinner (1996) using an agent-means-ends measurement approach. Capacity beliefs were significantly related to control beliefs $(r=.71)$ and strategy beliefs $(r=.78)$ at program onset. However, stronger correlations were evident between control beliefs and strategy beliefs at program onset $(r=.83)$, reflecting almost $70 \%$ shared variance. From a measurement perspective, individuals seem to be responding to these two constructs in a highly similar fashion. Therefore, regardless of whether participants responded to (a) an endpoint that was presented without the reference to the actions used to obtain longer range goals (control beliefs), (b) an endpoint when such actions were mentioned (strategy beliefs), or (c) an action or ability without mention of an endpoint, their responses were highly correlated.

In examining the relationships at Week 6 (midprogram), a slight differentiation among constructs emerged. The capacity and control beliefs and the capacity and strategy beliefs were still significantly correlated, but to a lesser extent than at program onset ( $r=.52$ and .60 , respectively). Thus, these relationships began to share less overlap over time. This was not the case for the relationship between strategy and control beliefs, however. These measures continued to be highly correlated at midprogram.

\section{Prediction of Exercise Attendance}

In order to examine the ability of the more explicitly measured aspects of control to predict exercise attendance, a priori hierarchical multiple-regression

Table 2 Correlations Among Control Measures, Behavioral Intention, and Exercise Attendance

Variable

2

3

4

Program Onset:

1. Control beliefs

$.83 * * *$

$.71 * * *$
$.78 * * *$

$.26^{*}$

.04

2. Strategy beliefs

3. Capacity beliefs

$.22 *$

$-.11$

4. Behavioral intention

$.28 * *$

.03

5. Attendance

Midprogram:

1. Control beliefs

2. Strategy beliefs

3. Capacity beliefs

4. Behavioral intention

5. Attendance

$.88 * * *$

$.52 * * *$
$.60^{* *}$

$.46^{* * * *}$

.14

$.45^{* *}$

.05

$.45^{* * *}$

Note. Program onset time $1 n=116$, and midprogram time $2 n=72$. $p$ s represent twotailed probability values.

${ }^{*} p<.05 .{ }^{* *} p<.01 . * * * p<.001$. 
procedures were used at both time points. Attendance was the criterion variable in all the regression models examined. However, because control beliefs and strategy beliefs share considerable variance and because they could contribute to the problem of multicollinearity in the prediction of the criterion variable, both beliefs were analyzed separately to evaluate their predictive utility. Therefore, as shown in Table 3, the first regression equation (Model A) contained the predictor variables of control beliefs and capacity beliefs, and the second equation (Model B) contained the strategy belief and capacity belief predictors. Both Model A and Model B also included the predictor of behavioral intention, consistent with the rationale and hypotheses described earlier. Models were examined for Weeks 1-5 and Weeks 6-10.

Results for the model that combined capacity beliefs with strategy beliefs (Model B) revealed that capacity beliefs accounted for a modest, but significant, $5 \%$ of the variation in attendance at onset $(p \leq .04)$ and $9 \%$ at midprogram $(p \leq$ .03 ). Behavioral intention significantly predicted attendance at program onset and midprogram in both Model A and Model B. Neither control nor strategy beliefs individually predicted attendance at onset or midprogram. Thus, the two beliefs that focussed on endpoints did not predict, whereas the belief that explicitly measured actions did predict behavior.

Table 3 Prediction of Behavior Using Control Measures and Behavioral Intention

\begin{tabular}{|c|c|c|c|c|c|}
\hline & $R_{\text {change }}^{2}$ & beta & $p$ & $R_{\text {adjusted }}^{2}$ & Mult $R$ \\
\hline \multicolumn{6}{|l|}{ Weeks 1-5: } \\
\hline Control & .00 & -.01 & .85 & & \\
\hline Capacity & .00 & .04 & .82 & & \\
\hline Behavioral intention & .08 & .40 & $.03 *$ & & \\
\hline Model A & & & $.05^{*}$ & .07 & .18 \\
\hline Strategy & .02 & -.43 & .20 & & \\
\hline Capacity & .05 & .36 & $.04 *$ & & \\
\hline Behavioral intention & .05 & .38 & $.04 *$ & & \\
\hline Model B & & & $.05^{*}$ & .08 & .27 \\
\hline \multicolumn{6}{|l|}{ Weeks 6-10: } \\
\hline Control & .03 & .03 & .24 & & \\
\hline Capacity & .05 & .25 & .11 & & \\
\hline Behavioral intention & .09 & .41 & $.01 * *$ & & \\
\hline Model A & & & $.05^{*}$ & .14 & .27 \\
\hline Strategy & .00 & -.16 & .67 & & \\
\hline Capacity & .09 & .37 & $.03 *$ & & \\
\hline Behavioral intention & .08 & .36 & $.04^{*}$ & & \\
\hline Model B & & & $.05^{*}$ & .12 & .30 \\
\hline
\end{tabular}

Note. Criterion variable $=$ attendance. Program onset time $1 n=116$, and midprogram time $2 n=72$.

${ }^{*} p<.05 . * * p<.01$. 
Table 4 Prediction of Behavior Using a Capacity Belief-Behavioral Intention Model

\begin{tabular}{lcclcl}
\hline & $R_{\text {change }}^{2}$ & beta & $p$ & $R_{\text {adjusted }}^{2}$ & Mult $R$ \\
\hline Weeks 1-5: & & & & & \\
$\quad$ Capacity beliefs & .05 & .37 & $.04^{*}$ & & \\
$\quad$ Behavioral intention & .09 & .41 & $.02^{*}$ & & \\
$\quad$ Model & & & $.03^{*}$ & .11 & .39 \\
Weeks 6-10: & .10 & .38 & $.02^{*}$ & & \\
Capacity beliefs & .09 & .36 & $.01^{* *}$ & & \\
Behavioral intention & & & $.01^{* *}$ & .16 & .43 \\
Model & & & & & \\
\hline
\end{tabular}

Note . Criterion variable $=$ attendance. Program onset time $1 n=116$, and midprogram time $2 n=72$.

$*_{p}<.05 . * p<.01$.

Given the results of the regression analyses at this point, and the fact that strategy and control beliefs accounted for minimal variance in the models tested (Models A and B), a reduced model excluding control beliefs and strategy beliefs was examined. This approach to model reduction is recommended by both Cohen (1992) and Tabachnick and Fidell (1996) as an appropriate strategy to maximize statistical power within a given sample. Table 4 illustrates the results of examining this reduced model in the prediction of attendance. At both onset and midprogram, capacity beliefs and behavioral intention were significant independent predictors of attendance when their independent contributions to the model were examined $\left(R_{\text {change }}^{2}\right)$. Also, they jointly contributed to the variance accounted for in the complete model at both onset and midprogram (model $R^{2}$ adjusted Week $1=.11, p=.03$, and model $R_{\text {adjusted }}^{2}$ Week $6=.16, p=.01$ ).

As hypothesized, capacity beliefs did predict exercise attendance, although most effect sizes detected were modest $\left(R^{2}\right.$ adjusted $=.08, .12, .11$ : see Cohen's (1988) effect-size conventions for $R^{2}=.02-12$ ). Furthermore, as hypothesized, a medium effect size (cf. Cohen, 1988; Green, 1991; $R^{2}=.13-.26$ ) was observed when the midprogram model of capacity beliefs and behavioral intention predicted exercise attendance (model $R^{2}$ adjusted $=.16$ ). This result is similar to the findings of other exercise studies that used self-efficacy and behavioral intention to predict exercise attendance (e.g., DuCharme \& Brawley, 1995; Poag-DuCharme \& Brawley, 1993).

\section{Discussion}

Although Skinner (1996) has suggested that an agent-means-ends approach might help distinguish control constructs, thereby offering more explicit measurement of constructs and, thus, better prediction, the results of this study do not support that contention. Control beliefs based on actions (capacity) and endpoints (control and strategy) were strongly related. Similarly, regardless of whether an endpoint was evaluated with reference to the necessary means (strategy beliefs) or 
without reference to the actions (control beliefs), the responses were highly similar. Perhaps, as Skinner (1995) suggested, even when behaviors (means) are not explicitly defined for the individual, evaluations of endpoints will still include some general appraisal of the means available.

With respect to the prediction of behavior, several relationships were evaluated. Neither control nor strategy beliefs contributed independently to predicting exercise attendance. In contrast, capacity beliefs and behavioral intention were found to be the primary predictors of attendance in the present study. It is not surprising that the best predictors of actual attendance appear to be measures of capacity beliefs and behavioral intention. First, these measures have strong correspondence with the criterion measure of attendance, because their items concern the frequency, actions, and time frame relevant to attendance. Second, this finding is similar to exercise-related effects observed in previous literature (Bandura, 1997; DuCharme \& Brawley, 1995; Godin, 1993; Maddux \& DuCharme, 1997; McAuley \& Courneya, 1993; Poag-DuCharme \& Brawley, 1993; Rodgers \& Brawley, 1996). Close scrutiny of operational definitions of the control concepts in those studies and reviews reveals that self-efficacy beliefs are highly similar to the recommended measurement of capacity beliefs. Based on the literature demonstrating that selfefficacy predicts attendance independently and additively with behavioral intention, the findings of the present study are consistent.

Maddux and DuCharme (1997) described the relationship between behavioral intention and self-efficacy (i.e., capacity beliefs) as follows. When the behavior or situation allows a person complete control over the behavior, intention alone should predict behavior. However, the less the person's volitional control over a behavior, the greater the importance of perceived behavioral control (i.e., selfefficacy or capacity beliefs), because it involves beliefs that one has both the resources and the opportunities to execute a behavior or attain a goal. In the exercise setting, where attendance frequency is often undermined by situational constraints, both behavioral intention and self-efficacy (capacity beliefs) will predict exerciserelated behavior. The results of the reduced-model analyses in the present study support this argument consistently at both program onset and midpoint.

Finally, this study represents the only investigation in the exercise literature that challenges Skinner's (1996) suggestions as offered through her integrative framework by empirically comparing the supposed explicit measurement advantages it offers and examining prediction of behavior using these more explicit measures. The results of this study underscore the arguments about the conceptual overlap of control constructs in the exercise literature and their place in Skinner's (1996) integrative framework (Biddle, 1999; Dawson et al., in press). It is clear that more work evaluating Skinner's (1996) proposals and other forms of control constructs in the exercise domain is needed so that we do not contribute to the conceptual ambiguities and measurement problems outlined in Skinner's (1996) review and do not accept presumed advantages of new methods of measurement without empirical tests (Brawley \& Martin, 1995).

\section{Acknowledgment}

The authors greatly appreciate the funding for this project through a Social Sciences and Humanities Research Council doctoral fellowship granted to the first author. 


\section{References}

Ajzen, I. (1988). Attitudes, personality, and behavior. Chicago: Dorsey Press.

Bandura, A. (1997). Self-efficacy: The exercise of control. New York: W.H. Freeman.

Bandura, A. (1986). Social foundations of thought and action: A social cognitive theory. Englewood Cliffs, NJ: Prentice-Hall.

Bandura, A. (1977). Self-efficacy: Toward a unifying theory of behavior change. Psychological Review, 84, 191-215.

Barone, D.F., Maddux, J.E., \& Snyder, C.R. (1997). Social cognitive psychology: History and current domains. New York: Plenum.

Biddle, S. (1999). Motivation and perception of control: Tracing its development and plotting its future in exercise and sport psychology. Journal of Sport \& Exercise Psychology, 21, 1-23.

Brawley, L.R. (1993). Introduction to the special issue: Application of social psychological theories to health and exercise behavior. Journal of Applied Sport Psychology, 5, 9598.

Brawley, L.R., \& Martin, K.M. (1995). The interface between social and sport psychology. The Sport Psychologist, 9, 469-497.

Cohen, J. (1992). A power primer. Psychological Bulletin, 112, 1155-1159.

Cohen, J. (1988). Statistical power analysis for the behavioral sciences (2nd ed.). New York: Academic Press.

Courneya, K.S., \& McAuley, E. (1993). Predicting physical activity from intention: Conceptual and methodological issues. Journal of Sport \& Exercise Psychology, 15, 50 62.

Dawson, K.A., \& Brawley, L.R. (2000). Examining the relationship between exercise goals, self-efficacy, and overt behavior with beginning exercisers. Journal of Applied Social Psychology, 30, 315-329.

Dawson, K.A., Gyurcsik, N., Culos-Reed, N., \& Brawley, L. (in press). Perceived control: A construct bridging theories of motivated behavior. In G. Roberts (Ed.), Exercise motivation. Champaign, IL: Human Kinetics.

Dishman, R.K. (1994). (Ed.). Advances in exercise adherence. Champaign, $\mathrm{L}$ : Human Kinetics.

Dishman, R.K. (1988). (Ed.). Exercise adherence: Its impact on public health. Champaign, IIL: Human Kinetics.

DuCharme, K.A., \& Brawley, L.R. (1995). Predicting the intentions and behavior of exercise initiates using two forms of self-efficacy. Journal of Behavioral Medicine, 18, 479-497.

Godin, G. (1993). The theories of reasoned action and planned behavior: Overview of findings, emerging research problems and usefulness for exercise promotion. Journal of Applied Sport Psychology, 5, 141-157.

Green, S.B. (1991). How many subjects does it take to do a regression analysis? Multivariate Behavioral Research, 26, 499-510.

Hausenblas, H.A., \& Carron, A.V. (1999). Eating disorder indices and athletes: An integration. Journal of Sport \& Exercise Psychology, 21, 230-258.

Maddux, J.E. (1993). Social cognitive models of health and exercise behavior: An introduction and review of conceptual issues. Journal of Applied Sport Psychology, 5, 116-140.

Maddux, J.E., Brawley, L.R., \& Boykin, A. (1995). Self-efficacy and health behavior: Prevention, promotion, and detection. In J. Maddux (Ed.), Self-efficacy, adaptation and adjustment: Theory, research, and application (pp. 173-202). New York: Plenum Press. 
Maddux, J.E., \& DuCharme, K.A. (1997). Behavioral intentions in theories of health behavior. In D.S. Gochman (Ed.), Handbook of health behavior research I: Personal and social determinants (pp. 133-151). New York: Plenum Press.

McAuley, E., \& Courneya, K. (1993). Adherence to exercise and physical activity as health promoting behaviors: Attitudinal and self-efficacy influences. Applied Preventive Psychology, 2, 65-77.

McAuley, E., \& Mihalko, S.L. (1998). Measuring exercise-related self-efficacy. In J. Duda (Ed.), Advances in sport and exercise psychology measurement (pp. 371-389). Morgantown, WV: Fitness Information Technology.

Poag-DuCharme, K.A., \& Brawley, L.R. (1994). Perceptions of the behavioral influence of goals: A mediational relationship to exercise. Journal of Applied Sport Psychology, 6, 32-50.

Poag-DuCharme, K.A., \& Brawley, L.R. (1993). Self-efficacy theory: Use in the prediction of exercise behavior in the community setting. Journal of Applied Sport Psychology, 5, 178-194.

Poag-DuCharme, K.A., Brawley, L.R., Rodgers, W., \& Robinson, K. (1992, October). Behavioral intention to exercise: Conceptualization and measurement. Paper presented at the annual meeting of the Association for the Advancement of Applied Sport Psychology, Colorado Springs, CO.

Pollock, M.L., Gaesser, G.A., Butcher, J.D., Despres, J.P., Dishman, R.K., Franklin, B.A., \& Ewing Garber, C. (1998). The recommended quantity and quality of exercise for developing and maintaining cardiorespiratory and muscular fitness, and flexibility in healthy adults. Medicine \& Science in Sports \& Exercise, 30, 975-991.

Rodgers, W., \& Brawley, L.R. (1996). The influence of outcome expectation and self-efficacy on the behavioral intentions of novice exercisers. Journal of Applied Social Psychology, 26, 618-634.

Rogers, R.W. (1975). A protection motivation theory of fear appeals and attitude change. Journal of Psychology, 91, 93-114.

Rogers, R.W., \& Prentice-Dunn, S. (1997). Protection motivation theory. In D.S. Gochman (Ed.), Handbook of health behavior research I: Personal and social determinants (pp. 113-132). New York: Plenum.

Rosenstock, I.M. (1974). Historical origins of the health belief model. Health Education Monographs, 2, 328-335.

Skinner, E.A. (1996). A guide to constructs of control. Journal of Personality and Social Psychology, 71, 549-570.

Skinner, E.A. (1995). Perceived control, motivation, and coping. Thousand Oaks, CA: Sage.

Skinner, E.A., Chapman, M., \& Baltes, P.B. (1988). Control, means-ends, and agency beliefs: A new conceptualization and its measurement during childhood. Journal of Personality and Social Psychology, 54, 117-133.

Strecher, V.J., Champion, V.L., \& Rosenstock, I.M. (1997). The health belief model and health behavior. In D.S. Gochman (Ed.), Handbook of health behavior research I: Personal and social determinants (pp. 71-92). New York: Plenum.

Tabachnick, B.G., \& Fidell, L.S. (1996). Using multivariate statistics (3rd ed.). New York: Harper Collins.

Manuscript submitted: October 24, 1998

Revision accepted: April 20, 2000 